\title{
CONCEPCIONES Y TIPOLOGÍA DE LAS PRESUNCIONES EN EL DERECHO CONTINENTAL*
}

\author{
Conceptions and tipologies of presumptions in civil law
}

Dr. Raymundo Gama Leyva**

\begin{abstract}
Resumen: Este artículo tiene como objetivo mostrar algunos problemas persistentes en el uso de las presunciones en el Derecho. De manera concreta, se plantea que el análisis de las presunciones está afectado por la ambigüedad en el uso de esta expresión en el lenguaje jurídico, así como por la diversidad de concepciones sobre las presunciones. En el artículo se critica la concepción tradicional de las presunciones como razonamientos o inferencias del legislador o del juez. A pesar del arraigo de esta concepción en la cultura jurídica continental, en el artículo se argumenta que se trata de una concepción insuficiente e inadecuada. Dicha concepción es insuficiente porque solo permite explicar la estructura del razonamiento presuntivo, pero no da cuenta del carácter y el funcionamiento de las reglas de presunción establecidas legal o jurisprudencialmente. Por otra parte, dicha concepción es inadecuada porque las presunciones legales no son inferencias que van de un hecho conocido a un hecho desconocido, sino reglas que obligan a considerar un hecho como probado, dispensando a quien se beneficia con la presunción de la carga de acreditar un hecho, trasladando la carga de la prueba a la contraparte que desee evitar que opere la presunción.
\end{abstract}

Palabras clave: Presunciones - razonamiento presuntivo - hecho presumido - carga de la prueba - regla de presunción - cultura jurídica - presunciones legales - presunciones jurisprudenciales.

Abstract: This article examines some persistent problems in the analysis of presumptions in the Civil Law tradition. On the one hand, it deals with the ambiguity of this expression in legal language as one of the main causes of legal controversy. On the other hand, it distinguishes to conceptions in the study of presumptions. Firstly, the traditional conception holds that presumptions are inferences of the legislator or the court drawn

\footnotetext{
* Este trabajo ofrece una reconstrucción general de la noción de presunción en la dogmática jurídica continental; tiene una función eminentemente descriptiva, en la medida en que trata de recoger la manera en que los juristas entienden y analizan, de hecho, el concepto de presunción. En este sentido, el trabajo no tiene la pretensión de establecer o privilegiar como "correcto" un determinado uso del término "presunción". Por el contrario, tiene la finalidad de advertir la ambigüedad en el uso de esta expresión y de someter a examen crítico la concepción tradicional de las presunciones en la dogmática jurídica a la luz de lo que se identifica como "concepción analítica de las presunciones". Esta concepción conduce en última instancia a un análisis individualizado de la tipología de las presunciones tradicionalmente utilizada en la cultura jurídica continental. Agradezco las observaciones formuladas por el dictaminador anónimo que revisó este trabajo.

** Doctor en derecho. Profesor de tiempo completo del Departamento Académico de Derecho del Instituto Tecnológico Autónomo de México, Ciudad de México, México. Correo electrónico: raymundo.gama@itam.mx
}

Este artículo fue recibido el 3 de septiembre de 2013, siendo aprobada su publicación con fecha 7 de enero de 2014. 
Gama - Concepciones y tipología de las presunciones...

from a known fact to an unknown fact. According to this view, it is possible to formulate a general concept of presumption (genus) that purports to be applicable to the different types of presumptions. This conception is criticized and confronted with an analytical conception of presumptions that proposes to examine each type of presumption individually. The article underlies the distinction between presumption rules and presumptive inferences and proposes an explanation for the main types of presumptions in the Civil Law tradition

Keywords: Presumption - presumptive reasoning - burden of proof - inference rebuttable presumptions - conclusive presumptions - permissible presumptions.

\section{La ambigüedad de la noción de presunción}

El análisis de la noción de presunción en el Derecho se dificulta, en gran medida, por la extraordinaria ambigüedad de esta expresión. Es un término que es empleado de distintas maneras y en diferentes contextos por los diversos operadores jurídicos (jueces, legisladores, abogados, autoridades, etc.). No reparar en ello está en la base de muchas falsas polémicas que se han suscitado entre los juristas. Es conveniente, por ello, comenzar advirtiendo algunas de las principales fuentes de ambigüedad en el uso de esta expresión.

a) Una primera fuente de ambigüedad se origina en el hecho de que el término "presunción" (al igual que otras expresiones como "prueba", "argumentación", "interpretación”) presenta la conocida ambigüedad proceso-producto. Esto quiere decir que utilizamos la misma expresión para referirnos tanto a la actividad de presumir, como el resultado de la actividad presuntiva. Se trata de una ambigüedad propia del uso cotidiano que se hace de dicha expresión pero que también está presente en el lenguaje jurídico. ${ }^{1}$ Para sortearla, algunos autores han estipulado reservar el uso de la noción de "presunción" para referirse a la actividad de presumir, mientras que el resultado de dicha actividad es identificado como "hecho presumido" o "hecho presunto". Pero esta convención no es siempre atendida y subsiste la utilización de la noción de "presunción" en los dos sentidos indicados. Conviene tener presente, por consiguiente, la distinción entre presunción como actividad y presunción como resultado.

\footnotetext{
${ }^{1}$ En ocasiones tal ambigüedad ha generado polémicas entre los juristas. Esto ocurre especialmente cuando se pretende que lo que está en el fondo no es una cuestión de ambigüedad, sino un problema conceptual relativo a la "correcta" definición de "presunción". Buena prueba de ello es la discusión que se presenta en sede dogmática respecto de si el instituto de la presunción ha de identificarse con la actividad presuntiva o bien con el resultado de dicha actividad, habiendo juristas que se decantan y argumentan a favor de una u otra interpretación. Así, mientras que algunos autores definen la presunción como una "actividad intelectual" (Cfr. SERRA DOMÍNGUEZ (1963), p. 78), otros la presentan como "el producto de un razonamiento lógico" (Cfr. PRIETO CASTRO y FERRÁNDIZ (1982), p. 700). No obstante, si el análisis de la noción de presunción en el Derecho se realiza desde una aproximación convencional, y por tanto no esencialista, del lenguaje podrá apreciarse que dicha controversia reposa no tanto en un desacuerdo genuino sobre el concepto de presunción, sino en un mero desacuerdo verbal.
} 
b) Una segunda fuente de ambigüedad que afecta el análisis de la noción de presunción en el Derecho deriva de la variedad de sentidos en los que se utiliza comúnmente esta expresión. Entre los significados más usuales estarían los siguientes. i) "Presunción" es utilizado en múltiples ocasiones en el sentido de sospecha o conjetura que se formula a partir de determinados indicios (e.g. "el cielo está nublado, las nubes están cargadas, presumo que lloverá"). En este primer sentido, "presunción" sería un término próximo al de "inferencia" (y en cierto modo también al de "hipótesis"). ii) En segundo lugar, el término "presunción" es utilizado también en el sentido de vanagloriarse o jactarse de tener alguna cualidad. No obstante, este segundo sentido es habitualmente excluido del discurso jurídico por considerar que carece de significación jurídica. ${ }^{2}$ iii) En una tercera acepción, "presunción" es utilizado para indicar que algo se acepta de manera anticipada (que se asume como válido o existente). Esta tercera acepción estaría relacionada con el significado etimológico de "presumir" (praesumptio: prae sumere), como equivalente a tomar, asumir o suponer anticipadamente.

c) Y en fin, si del uso que se hace de esta expresión en el lenguaje común nos trasladamos al lenguaje jurídico el panorama que se aprecia es, a grandes rasgos, el siguiente.

"Con el nombre de presunción -escribía Eduardo Pallares- la ley y la doctrina [y podría añadirse también la jurisprudencia] comprenden entidades jurídicas de naturaleza diversa, que en estricta lógica no pertenecen a un mismo género". ${ }^{3}$ Como consecuencia de ello, Pallares advertía que el término "presunción" no tenía un significado unívoco, sino multívoco, derivado de las distintas maneras en las que dicho término es entendido y utilizado por los distintos operadores jurídicos. Ahora bien, entre los distintos sentidos en los que se utiliza esta expresión en el lenguaje jurídico, hay tres en particular que merecen atención.

(i) Presunción como sinónimo de prueba inferior.- "Presunción" es entendido generalmente como sinónimo de "conjetura" y también de "indicio", especialmente por parte de la doctrina menos reciente. ${ }^{4}$ Una muestra clara al respecto puede leerse en la definición del diccionario jurídico de Fernández de León: "Presunción: Conjetura o indicio que se deduce, ya del modo como los hombres se conducen generalmente, ya de las leyes de la naturaleza".

\footnotetext{
2 SERra DOMÍNGUEZ (1963), p. 5.

${ }^{3} \mathrm{El}$ jurista mexicano ilustraba esta posición con los siguientes ejemplos: "Del hecho de que una persona vista elegantemente, use alhajas de gran valor y tenga un automóvil determinado, se presume que posee una cuantiosa fortuna". "El que posee un terreno tiene a su favor la presunción de ser propietario del mismo". "Lo resuelto por una sentencia ejecutoria constituye una presunción legal que no admite prueba en contrario". Cfr. PALLARES (1963).

${ }^{4}$ LESSONA (1964), p. 113.
} 
Gama - Concepciones y tipología de las presunciones...

Sin embargo, hay un uso peculiar que se presenta cuando "presunción" sigue siendo utilizado como equivalente de "conjetura" o "indicio", y también de "sospecha", pero con la peculiaridad de que, en este caso, "presunción" tiene una connotación marcadamente negativa. Se habla de presunción, desde esta perspectiva, para referirse a las inferencias que tienen un escaso valor probatorio o que equivalen a meras sospechas o suposiciones infundadas. En este sentido, "presunción" es entendido como sinónimo de "prueba inferior" o prueba semiplena, esto es, como una prueba que tiene un escaso valor probatorio. El carácter negativo e inferior asociado a la noción de presunción es característico de los sistemas probatorios de prueba legal que se impusieron durante la Edad Media, pero se trata de un uso que no es del todo infrecuente en el discurso jurídico actual. $^{5}$

(ii) Presunción como prueba indirecta.- En un sentido más extendido en la doctrina contemporánea, "presunción" hace referencia a un razonamiento probatorio de carácter indirecto en el que se considera como acreditado un hecho a partir de la prueba de otro hecho. Este segundo sentido se diferencia del anterior porque no atribuye a la noción de presunción una carga emotiva de carácter negativo. Desde esta perspectiva, la presunción es reconducida a la categoría de pruebas. Los juristas hablan en este sentido de "prueba por presunciones", "prueba presuntiva" o simplemente de "presunciones", calificándola como una prueba indirecta (y en ocasiones, como prueba crítica, en oposición a la prueba histórica). En este contexto "presunción" aparece como sinónimo de "prueba indiciaria" y de "prueba circunstancial". El que se emplee una expresión u otra depende, en algunos casos, de las convenciones de la propia doctrina. Así, mientras que es común que en el ámbito civil se hable de "presunciones", en el ámbito penal se habla de "prueba indiciaria" o "prueba circunstancial".

(iii) Presunción como regla vinculada con la distribución de la carga de la prueba.En una tercera acepción, "presunción" designa una regla que dispensa a una de las partes de la carga de probar un hecho jurídicamente relevante para efectos de la decisión y que transfiere a la contraparte la carga de acreditar lo contrario. Desde esta perspectiva, la noción de presunción aparece estrechamente vinculada con la noción de carga de la prueba. ${ }^{6}$

\footnotetext{
${ }^{5}$ LÉVY (1965). Un gran número de autores han puesto de relieve la desconfianza de los tribunales hacia las presunciones. Vid. al respecto, SERRA DomíngueZ (1963), p. 7; MuÑOZ SABATÉ (1983), p. 244 y MiRANDA ESTRAMPES (1997), p. 220. La desconfianza hacia las presunciones puede advertirse también en los tribunales mexicanos cuando la prueba debe ser plena "y no inferirse en base a presunciones". Cfr. Tesis 1a./J. 61/2007, Semanario Judicial de la Federación y su Gaceta, Novena Época, XXVI, julio de 2000, p. 178.

${ }^{6}$ Siguiendo esta orientación algunos juristas procuran reservar el uso de la noción de presunción para referirse a las presunciones establecidas en la ley (presunciones iuris), mientras que para designar el procedimiento probatorio que consiste en basar de un hecho hablan de prueba indirecta, prueba de indicios o prueba indiciaria Vid. en este sentido PRIETO CASTRO y FERRÁNDIZ (1982), p. 632 y MuÑoZ SABATÉ (1983), p. 243.
} 
A partir de lo anterior es posible apreciar que el término "presunción" tiene un significado bastante complejo como consecuencia de las distintas maneras y contextos en los que es entendido y utilizado por los distintos operadores jurídicos.

\section{Concepciones de las presunciones}

En la literatura jurídica es posible distinguir al menos dos concepciones de las presunciones. Cada una de estas concepciones ofrece maneras distintas de aproximarse al concepto de presunción. La primera concepción plantea que es posible reconstruir una noción general de presunción mediante la identificación de las propiedades que comúnmente caracterizan a los distintos tipos de presunción, de tal modo que dicha noción resulte adecuada para explicar las distintas figuras que los juristas convienen en identificar con el nombre de presunción. La segunda concepción duda de la posibilidad de construir una noción de tales características y aboga, en cambio, por examinar el concepto de presunción a partir del análisis de los distintos tipos de presunción en el Derecho.

\subsection{Concepción tradicional: las presunciones como razonamientos}

\section{a) Noción usual de presunción}

La concepción más extendida en la dogmática jurídica continental sostiene que las presunciones son razonamientos del legislador o del juez en los que se parte de un hecho conocido para determinar la existencia de un hecho ignorado. Esta inferencia sería posible gracias a la existencia de un vínculo entre el hecho conocido y el hecho desconocido que los juristas asocian con la noción de "máximas de la experiencia". Se trata de una manera de caracterizar las presunciones que es generalmente aceptada y compartida por los juristas, al grado de que representa un auténtico lugar común en la explicación estándar de las presunciones en el Derecho. ${ }^{7}$

Esta manera de concebir las presunciones encuentra un gran respaldo en la literatura jurídica. Un gran número de juristas conciben a las presunciones como "razonamientos", como "inferencias", como una "actividad" o un "proceso mental", como un "procedimiento lógico" o una "operación lógica" que lleva a

\footnotetext{
${ }^{7}$ Esta concepción encuentra un claro antecedente en la definición de presunción del Código Civil Francés. El artículo 1349 de este código establece que "Las presunciones son las consecuencias que la ley o el magistrado extrae de un hecho conocido para deducir un hecho desconocido". Dicha definición aparece también en el artículo 2727 del c.c. italiano, al igual que en muchos otros ordenamientos europeos y latinoamericanos. Dicha definición es frecuente en la legislación mexicana. Tal es el caso, por ejemplo de los códigos civiles y procesales de los Estados, al igual que en legislaciones federales como la Ley Federal del Trabajo (art. 830) y el Código de Comercio (art. 277).
} 
Gama - Concepciones y tipología de las presunciones...

cabo el legislador o el juez. ${ }^{8}$ La definición que formula Devis Echandía es clara en este sentido: "la presunción es un juicio lógico del legislador o del juez, en virtud del cual se considera como cierto o probable un hecho (lo segundo es presunción judicial o de hombre), con fundamento en las máximas generales de la experiencia que le indican cuál es el modo normal cómo se suceden las cosas o los hechos".?

Para estos autores, el concepto de presunción antes descrito sería aplicable a las distintas clases de presunción puesto que, a su juicio, todas las presunciones (o al menos las que califican como "verdaderas presunciones") son razonamientos de carácter probatorio que lleva a cabo el legislador o el juez. Señalan que a través de tales razonamientos el legislador o el juez acreditan un hecho gracias a la prueba de otro hecho y de la existencia de un vínculo entre ambos basado en máximas de experiencia. A partir de ello, se aboga por la configuración de un concepto general de presunción aplicable a las distintas clases de presunción. Además de ser general, se trataría de un concepto bomogéneo que agruparía los distintos tipos de presunciones bajo un género común. La única variación dependería en función de que la inferencia presuntiva estuviera a cargo del legislador -en términos generales y abstractos- o por el juez -para el caso concreto-.$^{10}$ Pero en los dos casos, los partidarios de esta concepción sostienen que se trataría de la misma operación intelectual.

\section{b) Estructura de las presunciones}

La noción de presunción antes apuntada es el punto de partida para sostener que las presunciones poseen una estructura característica que estaría presente en cualquier clase de presunción. Esta estructura estaría conformada por los siguientes tres elementos: un hecho base, un hecho presumido y un enlace entre ambos de carácter lógico. ${ }^{11} \mathrm{El}$ hecho base (hecho conocido o proposición base) es descrito como el punto de partida del razonamiento presuntivo que ha de realizar el legislador o el juez para formular una presunción. El hecho presumido (hecho desconocido o hecho presunto) representa el punto final de la presunción y es considerado tradicionalmente como un hecho difícil o imposible de acreditar o simplemente como un hecho no acreditado. Finalmente, el enlace está formado

\footnotetext{
${ }^{8}$ Entre la literatura más representativa Vid. Montero Aroca (2002); Álvarez SÁnChEZ DE Movellán (2007), p. 10; PALlares (1983), p. 419; SÁNCHEZ Pino (1995), p. 23; Eseverri MARTÍNEZ (1995), p. 7; ITALIA (1999), p. 1. Hablan de "operaciones lógico-deductivas" GARBERÍ LLOBREGAT y BUITRÓN RAMÍREZ (2004), p. 529.

9 DEVIS ECHANDía (1988), p. 694

10 TARUFFO (1991).

11 Claramente en esta línea, Montero Aroca sostiene que "[e]n todas las presunciones, sea cual fuera la clase de la misma, tienen que existir necesariamente: un hecho base o indicio, un hecho presumido y un nexo lógico entre los dos hechos", cfr. MONTERO AROCA (2002), p. 128. Entre los autores que parten de un concepto unitario de presunción y que analizan la estructura de las presunciones en general, Vid. SERRA DOMÍNGUEZ (1963), pp. 28 y ss.; SÁNCHEZ PINO (1995), pp. 46 y ss.; Oliva SANTOS y DíEZ-Picazo Jiménez (2004), p. 374; Climent Durán (2005), pp. 873 y ss. y, entre lo más reciente, Álvarez SÁnCHEZ de MOVELLÁn (2007), pp. 9 y ss.
} 
por un enunciado general que permite vincular el hecho base y el hecho presumido y que, a su juicio, estaría formado por máximas de experiencia.

\section{c) Clasificación de las presunciones}

Los partidarios de esta concepción consideran que el enlace de las presunciones es un componente fundamental no solo porque gracias a él es posible realizar la inferencia presuntiva, sino porque también resulta útil para clasificar las presunciones. En su opinión, las presunciones se clasifican en función del sujeto que establece el enlace entre el hecho base y el hecho presumido. ${ }^{12}$ Cuando el legislador es el sujeto que realiza el enlace se estará ante una presunción legal. En este tipo de presunciones el legislador determina previamente y con carácter general el enlace de la presunción y ordena al juez que dé por existente el hecho presumido cuando se haya acreditado el hecho base. En cambio, cuando el enlace lo realiza el juez se estará ante una presunción judicial. En este caso, es el propio juez el que se encarga de determinar el enlace en cada caso concreto.

\section{d) Concepto unitario de presunción e identidad conceptual de las presunciones legales y judiciales}

Como corolario de las tesis anteriores se encuentran las dos siguientes afirmaciones. Por un lado, la pretensión de un concepto unitario de presunción. Por el otro, la asimilación conceptual de las presunciones legales y judiciales.

La configuración de un concepto unitario de presunción se plantea como una exigencia metodológica necesaria para comprender a cabalidad este instituto, así como la vía idónea para poder explicar las distintas modalidades de presunciones. Se afirma en este sentido que "es necesario alcanzar un concepto único y global para dicha institución", ${ }_{13}$ que "la presunción admite un concepto unitario, tanto en su estructura, como en su dinámica procedimental, que engloba tanto a las presunciones legales como a las judiciales"" así como que "debe buscarse un concepto de presunción lo suficientemente amplio para que entren en él todas las hipótesis de presunción y no solo algunas". ${ }^{15}$ Junto a este tipo de

\footnotetext{
12 Claramente en este sentido, Serra Domínguez (1963), p. 39: "La única distinción que verdaderamente hay que considerar como relevante es la que se refiere al enlace entre la afirmación base y la afirmación presumida. Pero no atendiendo a la misma naturaleza del enlace, sino más bien al sujeto que lo establece (...) No interesa tanto la fuente del enlace, sino que el enlace se haya efectuado. En cambio, sí tiene una gran importancia el sujeto que ha intervenido en la elección de la máxima de experiencia integradora del enlace. Normalmente tal máxima será elegida y aplicada por la misma persona que debe efectuar dicho enlace, es decir, por la persona del juzgador. Pero en ciertos casos la elección de la máxima de experiencia a paliar a una afirmación base determinada no es elegida por el juzgador, sino por el legislador, quedándole al primero únicamente la posibilidad de aplicación de dicha máxima al caso concreto planteado".

${ }^{13}$ SÁNCHEZ PINO (1995), pp. 22-23.

${ }^{14}$ Climent Durán (2005), p. 870.

${ }^{15}$ CARRERAS (1962), p. 341.
} 
Gama - Concepciones y tipología de las presunciones...

planteamientos se subraya la idea de que habría un conjunto de propiedades características que comparten los distintos tipos de presunciones, lo que justificaría agruparlas en torno a un mismo concepto. ${ }^{16}$

Centrándonos ahora en la asimilación conceptual entre presunciones legales y judiciales, se sostiene que ambas consisten en inferencias que parten de un hecho conocido para llegar a un hecho desconocido y se vinculan a través de una máxima de experiencia, con lo cual, "su naturaleza es la misma, tienen el mismo fundamento y el mismo carácter lógico, una y otra son un juicio de probabilidad". ${ }^{17}$

En la doctrina más reciente, por lo demás, pueden detectarse dos argumentos a favor de la asimilación conceptual de las presunciones legales y judiciales. El primer argumento es que los dos tipos de presunción tienen la misma naturaleza porque presentan una estructura común, conformada por un hecho base, un hecho presumido y un vínculo entre ambos. La única diferencia entre estos dos tipos de presunciones consistiría en el sujeto que establece el enlace, ya sea el legislador, en las presunciones legales o el juez, en las presunciones judiciales. Pero en uno y otro caso -se sostiene- el resultado es el mismo. ${ }^{18}$ El segundo argumento es que ambos tipos de presunción persiguen el mismo fin -acreditar un hecho de manera indirecta- y que el resultado que se obtiene en ambos casos es el mismo -dado que el enlace establecido por el legislador es el que hubiera establecido el juez para un determinado caso concreto-.

\footnotetext{
16 Claramente en este sentido se afirma que "cuando en la ciencia del derecho se utilizan repetidamente términos idénticos para designar situaciones o problemas distintos, es más avisado admitir que entre unos y otros existe un genus común, que escindir totalmente los fenómenos y atribuirles naturaleza distinta o negar la existencia de un grupo o categoría". Cfr. CARRERAS (1962). Se adhieren a la tesis de este autor Oliva SANTos y DíEZ-PiCAZO JimÉNEZ (2004), p. 375 y Álvarez SÁNCHEZ DE MOVELLÁN (2007), p. 33.

17 RAMPONI (1890), p. 21.

18 Cfr. Serra Domínguez (1963), p. 42: “Tanto las presunciones legales como las judiciales se caracterizan por su concreción. En las presunciones legales se establecen dos afirmaciones sumamente concretas, y se declara la existencia de un enlace entre ellas, ni más ni menos que ocurre en las presunciones judiciales. El motivo que determina tal enlace es idéntico tanto en unos como en otros: la existencia de una relación causal o lógica entre la afirmación base y la presumida. Idénticos son los criterios de experiencia utilizados en unas y otras. Su estructura no puede ser más semejante". Serra Domínguez reiteraba esta tesis al señalar que "la identidad estructural entre la presunción legal y la judicial debe forzosamente conducir a una identidad de naturaleza, siendo exclusivamente criterios de oportunidad y seguridad jurídica los que han movido al legislador a establecer imperativamente una presunción que hubiera podido igualmente ser utilizada por el propio juez”, en SERRA DOMÍNGUEZ (1991), p. 630. Este argumento se encuentra ampliamente difundido en la doctrina española. Vid. Oliva SANTOS y DíEZ-PiCAZO JimÉNEZ (2004), p. 374; CLIMENT DURÁN (2005), p. 873. La monografía más reciente sobre las presunciones se adhiere todavía a esta corriente: cfr. ÁlvAREZ SÁNCHEZ DE MOVELLÁn (2007), p. 34.
} 
Estos dos argumentos se vinculan con un planteamiento que se repite a menudo en la literatura jurídica, a saber, que entre las presunciones legales y judiciales solo habría una diferencia de grado, puesto que las primeras serían o bien una generalización y sistematización de las presunciones judiciales, o bien una cristalización de una máxima de experiencia utilizada previamente por el juez. Es ilustrativa en este punto la opinión de Francesco Carnelutti cuando señala que "la presunción legal (iuris) no difiere de la presunción simple (bominis) más que en cuanto a la regla de experiencia en virtud de la cual el juez deduce del indicio el becho a probar está fijada en una regla de derecho". ${ }^{19}$

\subsection{Concepción plural de las presunciones: el rechazo de un concepto homogéneo de presunción}

La concepción de las presunciones anteriormente descrita representa la manera en que los juristas entienden y explican tradicionalmente las presunciones. Una concepción que, como hemos dicho, está plenamente arraigada en la dogmática jurídica continental. Sin embargo, no es esta la única manera de entender las presunciones en la dogmática continental, ni se trata de una postura que esté exenta de críticas por parte de otros sectores doctrinales.

Bajo una segunda concepción de las presunciones es posible agrupar a todas aquellas posiciones doctrinales que se caracterizan por sostener los dos puntos siguientes. Primero, por renunciar a la posibilidad de construir un concepto general de presunción que resulte adecuado para dar cuenta de los distintos tipos de presunciones en el Derecho y por rechazar la asimilación conceptual entre presunciones legales y judiciales. Segundo, por considerar que la vía más adecuada para explorar el concepto de presunción en el Derecho es a través del examen individual de los diferentes tipos de presunción. ${ }^{20}$

La concepción tradicional de las presunciones suscita, para algunos autores, las siguientes interrogantes: ¿Hasta qué punto es adecuada la noción tradicional de presunción para dar cuenta de las presunciones en el Derecho? ¿Cuál es su capacidad explicativa? ¿Qué es lo que explica y lo que no? ¿Si no es adecuada, cuál sería una posible alternativa? Respecto de estas cuestiones, los autores argumentan lo siguiente.

\footnotetext{
19 CARnelutTi (1982), p. 200.

20 Los principales argumentos que se han elaborado en contra del concepto homogéneo de presunción han sido desarrollados principalmente en la doctrina italiana. Vid. al respecto, SACCO (1957); Andrioli (1966); TARufFo (1991); Comoglio (2005); PatTi (1987). Prácticamente podría decirse que, salvo algunas excepciones (cfr. ITALIA (1999)) los juristas italianos han abandonado la concepción tradicional de las presunciones. Vid. LiEBMAN (2007), p. 95 y MANDRIOLI (2006), pp. 183-184. La situación que se aprecia fuera del ámbito italiano es mucho más variada, en gran medida porque la concepción tradicional de las presunciones continúa siendo la posición dominante en la cultura jurídica del derecho continental. Aun con esta situación, son cada vez más frecuentes las voces que asumen una posición crítica respecto de una o varias de las tesis defendidas por la concepción tradicional.
} 
Gama - Concepciones y tipología de las presunciones...

La noción de presunción como razonamiento que va de un hecho conocido a un hecho desconocido es adecuada en la medida en que clarifica la estructura inferencial de las presunciones como un mecanismo probatorio de carácter indirecto de los hechos. Resulta problemática, sin embargo, cuando se pretende que esta noción sea aplicable a las presunciones legales.

Como hemos visto, al concebir las presunciones como razonamientos del legislador o del juez que van de un hecho conocido a un hecho desconocido los autores postulan un concepto general de presunción que sería aplicable a las distintas clases de presunciones y en el que la única diferencia específica estriba en que el sujeto que realiza la inferencia presuntiva sea el legislador o el juez. A juicio de un importante sector doctrinal, sin embargo, esta equiparación conceptual es totalmente inadecuada y "proviene de un error conceptual consistente en considerar idénticos fenómenos que, en realidad, son distintos". ${ }^{21}$

$\mathrm{Al}$ respecto, se señala que el concepto de presunción como inferencia que va del hecho conocido al hecho desconocido (o de un hecho base a un hecho presumido) es adecuado para explicar las presunciones formuladas por el juez, esto es, las presunciones simples (o judiciales). Sin embargo, esta noción no resulta adecuada para explicar qué son y cómo operan las presunciones legales.

No resulta adecuada, en primer término, porque la alusión a un razonamiento presuntivo realizado por el legislador serviría eventualmente como instrumento interpretativo de la ratio de la norma que establece la presunción, mientras que el esquema presuntivo que tiene lugar en las presunciones judiciales constituye "el mecanismo de control de la lógica del juez en los límites previstos por el ordenamiento jurídico". ${ }^{22}$ Dicha remisión tiene sentido para dar cuenta del plano explicativo o justificativo de la norma presuntiva, pero no resulta adecuada para explicar qué son y cómo operan las presunciones establecidas por el legislador.

En segundo lugar, los partidarios de la concepción tradicional de las presunciones reconstruyen un concepto general de presunción a partir de la identificación de los elementos o propiedades que, a su juicio, estarían presentes en las distintas clases de presunciones. Tales elementos son extraídos de los componentes estructurales de las presunciones: un hecho base, un hecho presumido y un enlace formado por máximas de experiencia. El potencial explicativo de esta reconstrucción -se argumenta desde la concepción ahora examinada- es bastante limitado. Por un lado, porque un gran número de presunciones legales no responden a la estructura hecho base-hecho presumido. Dos ejemplos paradigmáticos son la presunción de inocencia y la presunción de buena fe. En este tipo de reglas no se exige la prueba de un hecho base como

21 TARUfFO (2002), p. 471.

22 ANDRIOLI (1966), p. 767. 
requisito para que opere la presunción. ${ }^{23}$ Pero incluso limitándonos a los supuestos que responden a dicha estructura, ha de reconocerse que el hecho base de la presunción no opera en muchos casos como indicio o hecho conocido del que pueda inferirse el hecho desconocido. Por lo demás, la presencia de un enlace formado por máximas de la experiencia tampoco se presenta como un componente necesario de las presunciones legales. Muchas de ellas son establecidas a partir de consideraciones de distinta índole, i.e., procesales, institucionales, valorativas, etc., no sólo máximas que expresan regularidades empíricas. Para los partidarios de la concepción analítica, decir que todas las presunciones se fundamentan en un enlace basado en máximas de experiencia proporciona una imagen bastante reducida del número de presunciones en el Derecho y lo que sería más cuestionable, ofrecería una imagen distorsionada de la función que desempeñan. ${ }^{24}$

En tercer lugar, se argumenta que la noción tradicional de presunción no permite dar cuenta del carácter normativo de las presunciones legales. Al establecer una presunción el legislador no se limita a formular una inferencia más o menos razonable, sino que establece una norma jurídica. Se trata de una explicación que pasa por alto que las presunciones legales son normas jurídicas, no inferencias del legislador y que como tales su función consiste en determinar consecuencias jurídicas que están previstas en las normas.

De este último argumento se desprende la diferencia conceptual de las presunciones legales y las presunciones simples (o judiciales). ${ }^{25}$ Las presunciones legales (y, en general, las normas de presunción con independencia de la fuente que las establece, i.e. legal, jurisprudencial, convencional) no son una inferencia que va de un hecho conocido a un hecho desconocido, sino una regla jurídica que dispensa de la necesidad de acreditar un hecho y que traslada al oponente la carga de la prueba de lo contrario. Las presunciones simples, por el contrario, sí consisten en un razonamiento en el que la prueba de un hecho sirve como sustento para inferir la existencia de otro hecho. Las presunciones legales, por tanto, no proporcionan elementos de prueba, es decir, no son un instrumento cognoscitivo para la determinación de los hechos (i.e. no proporcionan información acerca de cómo ocurrieron determinados hechos). A diferencia de ello, las presunciones simples sí proporcionan elementos de prueba y producen

23 No es casual que a partir de esta circunstancia los autores distingan entre verdaderas presunciones o presunciones en sentido estricto (aquellas que responden a la estructura tradicional) y las llamadas verdades interinas (como la presunción de buena fe). Esta distinción es entendida en un sentido débil cuando se pone de relieve que unas y otras son normas que excluyen la necesidad de acreditar un hecho presumido y que trasladan la carga de la prueba a la contraparte. Vid. al respecto, MICHELI (1961), p. 196; FABBRINI (1991), p. 931.

24 En este sentido, conviene recordar la objeción de Sacco, en el sentido de que para que la presunción legal pudiera considerarse como una inferencia del legislador debería subsistir la premisa mayor del silogismo, la máxima de la experiencia, y la premisa menor del mismo, el hecho conocido del que parte la presunción. Cfr. SACCO (1957), pp. 407-410.

25 TARUfFO (1991). 
Gama - Concepciones y tipología de las presunciones...

consecuencias en el plano de la determinación de los hechos. La clave para entender la naturaleza de las presunciones legales se encuentra en su carácter de normas jurídicas. La clave para entender las presunciones simples es que se trata de inferencias cuya solidez dependerá en gran medida de la máxima de experiencia utilizada.

La consecuencia inmediata que se sigue de asumir estas tesis es que no habría un único concepto de presunción en el Derecho, ni una noción general de presunción que resulte adecuada para explicar las distintas figuras que los juristas convienen en identificar con el uso de dicha expresión. Por el contrario, en la propuesta ahora examinada, el análisis del concepto de presunción se resuelve en el examen concreto de los distintos tipos de presunción, así como en el análisis de sus características y de su funcionamiento. De manera paradigmática, en la tipología de presunciones en el Derecho Continental se encuentran i) las presunciones legales absolutas, ii) las presunciones legales relativas y las presunciones jurisprudenciales y iii) las presunciones simples.

\section{Tipología de las presunciones en el Derecho Continental}

\subsection{Presunciones legales absolutas}

Dentro de las presunciones legales se distingue habitualmente entre presunciones relativas (iuris tantum) y absolutas (iuris et de iure). La diferencia entre unas y otras se establece diciendo que las primeras admiten prueba en contrario, mientras que las segundas excluyen toda posibilidad de desvirtuar la presunción. ${ }^{26}$ La doctrina considera comúnmente que las presunciones absolutas forman parte del derecho sustantivo y que no tienen repercusiones en el ámbito procesal probatorio. Por lo demás, el rechazo de la noción de presunción absoluta y su exclusión del ámbito de las presunciones está ampliamente extendido en la literatura jurídica. La principal razón de esta exclusión es que una de las características definitorias de las presunciones es su derrotabilidad, por lo que resulta contradictorio hablar de una presunción que no puede ser destruida mediante prueba en contrario. ${ }^{27}$ Todas estas ideas constituyen un lugar común en la literatura jurídica. Pero llama la atención que a pesar de las reacciones tan encontradas que suscita, los juristas

\footnotetext{
${ }^{26}$ Esta es la manera en que las legislaciones trazan la distinción entre dos tipos de presunciones legales en función de que admitan o no prueba en contrario. Al respecto, se ha puesto de relieve que el legislador insiste en la idea de configurar un concepto unitario de presunción al ocuparse de las presunciones legales, sugiriendo que la única variación al interior de estas últimas deriva de la admisibilidad o de la exclusión de la prueba en contrario. En contra de idea se argumenta, como se verá, que habría una diferencia mucho más profunda entre estas dos figuras. Sobre ello vid. TARUFFO (1991), pp. 1 y ss.

${ }^{27}$ Escribe Serra Domínguez en este sentido: "Estando la presunción íntimamente relacionada con la prueba, se comprende que cualquier disposición legal que prohíba la prueba de lo contrario, por esta simple circunstancia no puede ser considerada como tal presunción". Cfr. SERRA DOMÍNGUEZ (1963), p. 379.
} 
sigan incluyendo esta categoría al explicar las distintas clases de presunción, así como el hecho de que continúe utilizándose dicha noción en el lenguaje jurídico. Por ello, es conveniente examinar a grandes rasgos la noción de presunción absoluta, explicar cómo operan este tipo de presunciones y explorar cuál es su vinculación con el concepto de presunción.

En la literatura jurídica se sostiene habitualmente que las presunciones absolutas no son verdaderas presunciones sino normas, prescripciones $\mathrm{o}$ mandatos legislativos de carácter sustantivo o material, cuya función consiste en la aplicación del derecho objetivo. ${ }^{28} \mathrm{El}$ rasgo peculiar que tendrían estas normas -se sostiene- es que son formuladas por el legislador en un lenguaje presuntivo. Pero la manera en que operan es esencialmente la misma, son normas jurídicas que anudan una consecuencia jurídica a un determinado supuesto de hecho. ${ }^{29}$

Esta explicación es útil en la medida en que proporciona una explicación inicial de la manera en que operan este tipo de presunciones, pero requiere algunas precisiones. Entre las interrogantes que habría que tener en cuenta estarían las siguientes: ¿cuál es la peculiaridad de las presunciones absolutas?, ¿qué las distingue de otro tipo de normas? ¿En qué se diferencian las presunciones absolutas y las presunciones relativas? En el discurso de la propia doctrina encontramos algunas pistas para afrontar estas cuestiones.

$\mathrm{Al}$ respecto, se ha puesto de relieve que las presunciones absolutas son un mecanismo al que recurre el legislador para simplificar la aplicación de una norma jurídica. ${ }^{30}$ Este mecanismo opera mediante la modificación de los presupuestos fácticos que la norma contempla para la producción de efectos jurídicos. Tal modificación opera, por un lado, extrayendo el hecho presumido como requisito de la aplicación de la norma, sustituyéndolo por otro hecho (o conjunto de hechos) de cuya prueba se condiciona la aplicación de la norma. Esto supone que la parte que se favorece con la presunción no necesita acreditar el hecho presumido, siendo suficiente con probar los hechos que sirven de base a la presunción para que se produzcan los efectos jurídicos previstos por la norma en cuestión.

Los autores explican que a través de la operación antes descrita se produce una equiparación (o asimilación) entre el hecho base y el hecho presumido, de tal manera que acreditar el primero (el hecho base) cuenta como -o tiene el mismo efecto- que si se acreditara el hecho presumido. Se dice en este sentido que las

\footnotetext{
${ }^{28}$ LESSONA (1964), p. 232.

${ }^{29}$ En algunos casos, esta consecuencia jurídica consiste en la declaración de nulidad de un acto o en la negación de una acción en juicio. Es relevante al respecto la opinión de Couture, cuando señala que la presunción absoluta es un ejemplo típico de imputación normativa. Cfr. CoUTURE (1993), p. 80.

30 Se trata de una tesis recurrente en la doctrina italiana. Vid. especialmente MiCHELI (1961), p. 196; ANDRIOLI (1966), p. 766; VERDE (1974), pp. 220-22; CORDOPATRI (1986), p. 290 y VALLEBONA (1988), pp. 14-15.
} 
Gama - Concepciones y tipología de las presunciones...

presunciones absolutas transfieren la consecuencia jurídica prevista para un hecho o un estado de cosas descritos en el hecho presumido, para el hecho o estado de cosas previsto en el hecho base, equiparando los efectos jurídicos de ambos. ${ }^{31} \mathrm{O}$ como señala Giovanna Fabbrini, las presunciones absolutas operan mediante la indicación de un hecho como directamente constitutivo de otro hecho. ${ }^{32}$

Para ilustrar lo anterior con un ejemplo, proveniente del derecho fiscal mexicano, el Código Fiscal de la Federación da a las personas morales la posibilidad de presentar documentos digitales a las autoridades tributarias en los trámites fiscales que realicen (arts. 17 y 19-A). Tales documentos digitales deberán contener una firma electrónica avanzada que sustituye a la firma autógrafa y que garantiza la integridad del documento. De esta manera, los documentos digitales presentados que contienen una firma electrónica avanzada producen el mismo efecto que los documentos con firma autógrafa. Pero el código establece una previsión adicional al señalar que "[s]e presumirá sin que se admita prueba en contrario" que los documentos digitales que contengan una firma electrónica fueron presentados por las personas encargadas de la administración de la persona moral. Es decir, que presentar un documento digital con la firma electrónica avanzada cuenta como, o equivale a, que dicho documento ha sido presentado por el administrador de la empresa; atribuye los efectos jurídicos previstos para un estado de cosas a ("documentos presentados por el administrador") a un estado de cosas b ("documentos digitales con firma electrónica avanzada").

Si esta es la manera como operan las presunciones absolutas queda por examinar cuál es su relación con la noción de presunción y qué es lo que las diferencia de las presunciones relativas. Al respecto, se ha argumentado que la diferencia entre las presunciones absolutas y relativas va más allá de la exclusión o admisión de prueba en contrario. Se señala en este sentido que mientras estas últimas son "normas que afirman un hecho como verdadero salvo prueba en contrario, las primeras no son establecidas por normas que afirman un hecho como verdadero excluyendo la prueba en contrario". Es decir, las presunciones

\footnotetext{
31 Sobre ello, Rosenberg (2002), p. 248 y FABBrini (1991), p. 920. En este sentido, se señala que esta técnica legislativa obedece a un favor legis establecido en beneficio de ciertos sujetos o de determinado tipo de situaciones jurídicas. Un beneficio que se aprecia, por un lado, en el nivel de la propia regla, con la sustitución de un hecho oscuro, ambiguo y difícil o imposible de acreditar que es calificado por la norma como relevante para la producción de efectos jurídicos, por un hecho claro, preciso y fácilmente individualizable al que se vinculan las consecuencias jurídicas del primero. $\mathrm{Y}$ en el plano del proceso, este mecanismo se presenta como instrumento para facilitar el cumplimiento de las cargas probatorias que de otro modo podría resultar sumamente difícil o inconveniente. Pero debe tenerse presente que la atenuación de las cargas probatorias es resultado de la modificación de la hipótesis normativa y no el efecto directo de la presunción.

32 FABBRINI (1991). Desde esta perspectiva, las presunciones absolutas se asemejan a lo que, en el ámbito de la teoría del Derecho, se conoce como reglas constitutivas, en la medida en que se establece una situación de hecho o un determinado estado de cosas que ha de verificarse para que tenga lugar un determinado resultado institucional. Vid al respecto, AGUILÓ (1999).

33 TARUFFO (1991).
} 
relativas son normas que establecen una presunción: obligan a considerar como probado un hecho hasta en tanto no se acredite lo contrario, ya sea a partir de la prueba de un hecho base (como en la presunción de paternidad respecto de los hijos nacidos dentro del matrimonio), o bien sin la necesidad de acreditar ningún hecho base (como en la presunción de buena fe).

Las presunciones absolutas, en cambio, no establecen una presunción, sino que instauran una consecuencia jurídica determinada sobre la base de un razonamiento presuntivo que se supone ha sido formulado por el legislador. Dicho en otros términos, en las presunciones relativas la presunción forma parte del contenido de la norma que establece la presunción. En las presunciones absolutas la presunción no forma parte del contenido de la norma, sino que constituye la premisa, la ratio sirve para explicar o justificar los motivos que condujeron a la creación de una norma. ${ }^{34}$

Si se tiene en cuenta lo anterior puede abordarse con facilidad la relación entre las presunciones absolutas y las ficciones. La doctrina ha diferenciado tradicionalmente estas dos figuras diciendo que las ficciones obligan a dar por cierto un hecho reconocidamente falso, mientras que las presunciones absolutas dan por cierto un hecho posible y eventualmente probable. Sin embargo, dicha distinción solo se mantiene en el plano interpretativo o explicativo de la ratio legis, esto es, en el nivel de la formación de la norma, sin que la verdad "presunta" o "ficticia" de un hecho determinado trascienda al contenido concreto de las normas que las establecen, ni en los efectos jurídicos que producen. ${ }^{35}$ Más allá de ello, las presunciones absolutas y las ficciones operan de la misma forma. En ambos casos se produce una asimilación entre dos hechos o estados de cosas. En palabras de Leo Rosenberg, son "preceptos jurídicos que transfieren la consecuencia jurídica determinada para el estado de cosas $a$ al estado de $\cos a s b$, equiparando el estado $b$ al estado a, al decir que $b$ es considerado como $a^{3}{ }^{36}$

\section{Presunciones legales relativas y presunciones jurisprudenciales}

El estudio de las presunciones legales relativas en la dogmática jurídica continental ha estado vinculado con el del concepto de carga de la prueba. De hecho, buena parte de las aportaciones más importantes que se han hecho en el terreno de las

\footnotetext{
${ }^{34}$ Ibid.

35 Como observa Taruffo, "en ambos casos las normas regulan directamente un determinado aspecto de la hipótesis normativa, sin afirmar expresamente la verdad 'presunta' o 'ficticia' del hecho”. Cfr. TARUfFo (1991), p. 2. Sobre este punto, vid. también SACCO (1957), p. 414 y ANDRIOLI (1966), p. 768. Entre lo más reciente véase asimismo VERDE (1971), p. 120 y FABBRINI (1996), p. 282. En la doctrina española, la posición más representativa es de Serra Domínguez, cuando señala que no existe diferencia alguna entre ambas figuras en cuanto a los efectos jurídicos que produce una y otra, "la única distinción que las separa es más bien anterior a su formación y responde a la distinta causa que las ha motivado". Cfr. SERRA DOMínguez (1963), p. 71.

${ }^{36}$ Rosenberg (2002), p. 248.
} 
Gama - Concepciones y tipología de las presunciones...

presunciones legales provienen de investigaciones sobre la noción de carga de la prueba. Esta vinculación se explica porque un aspecto característico del funcionamiento de las presunciones relativas es, precisamente, el efecto que producen en la carga de la prueba. Una investigación minuciosa de este tipo de presunciones requeriría examinar previamente la noción de carga de la prueba. A pesar de ello, un examen general de este tipo de presunciones puede resultar relevante en el presente contexto.

Los autores coinciden en que las presunciones legales relativas se caracterizan por dos notas distintivas. En primer término, dichas presunciones dispensan a una de las partes de la necesidad de probar un hecho, concretamente, el hecho presumido. La dispensa de prueba se traduce en que el hecho presumido deja de formar parte de los presupuestos exigidos por la norma para la producción de determinados efectos jurídicos. Este fenómeno se conoce en la doctrina continental como relevatio ab onere probandi. En segundo lugar, las presunciones legales relativas se caracterizan por trasladar a la contraparte la carga de aportar prueba en contrario para desvirtuar la presunción, a fin de evitar que se produzcan los efectos jurídicos que la norma prevé. En otros términos, las presunciones legales relativas se caracterizan por invertir la carga de la prueba a la contraparte. ${ }^{37}$

Hay, por lo demás, una característica adicional que es propia de las presunciones legales relativas y que las distingue de las presunciones simples. A diferencia de estas últimas, las presunciones legales relativas no son inferencias que parten de un hecho conocido a un hecho conocido y no representan una modalidad de conocimiento de los hechos. ${ }^{38}$ En este sentido, las presunciones legales relativas son, por tanto, reglas jurídicas, no inferencias sobre la ocurrencia de los hechos.

Estas presunciones obligan a reconocer como existente un hecho o un estado de cosas cuando se acredita previamente otro hecho o estado de cosas, o bien simplemente en ausencia de prueba en contrario. ${ }^{39}$ Así, por ejemplo, al acreditar la posesión actual y la posesión en un tiempo anterior, se presume que la posesión se mantuvo durante el tiempo intermedio (art. 800 C.C.). Del mismo modo, la presunción de buena fe en la posesión exime al poseedor de un bien de

37 En la literatura jurídica, vid. especialmente LESSONA (1964), pp. 315-316. Estas dos notas aparecen claramente discernidas en el discurso del legislador. A manera de ejemplo, la presunción de buena fe en la posesión (art. 807 del Código Civil Federal) exonera al poseedor de la carga de acreditar la buena fe y traslada a la contraparte la carga de acreditar la mala fe si desea evitar que se produzcan los efectos jurídicos que derivan de la posesión de buena fe, como el derecho de hacer suyos los frutos percibidos, de retirar las mejoras voluntarias, etc.

38 TARUFFO (1991).

39 Esta diferencia estructural ha llevado a la doctrina a distinguir entre presunciones en sentido estricto -aquellas que se componen de un hecho base y un hecho presumido- y las llamadas verdades interinas, que obligan a reconocer la existencia del hecho presumido sin que tenga que acreditarse otro hecho. En la literatura jurídica estas últimas son asimiladas a reglas de carga de la prueba. Vid. especialmente MiCHELI (1961) y FABBRINI (1991). 
la necesidad de acreditar su buena fe e impone a la contraparte la carga de acreditar la mala fe si quiere evitar que se produzcan los efectos jurídicos que derivan de la posesión de buena fe (por ejemplo, el derecho de hacer suyos los frutos percibidos, que se le abonen todos los gastos necesarios y poder retirar las mejoras voluntarias (art. 807, 810, 811 C.C.).

Por otra parte, son múltiples las razones por las que el legislador establece presunciones legales relativas: para corregir un desequilibrio entre las partes, para facilitar la aplicación de las normas en supuestos en los que la prueba de los hechos resulta sumamente difícil o imposible; porque la presunción se corresponde con lo que se considera que ocurre normalmente o con mayor probabilidad; para garantizar el reconocimiento de derechos o de situaciones que se consideran valiosas desde un punto de vista social, institucional, etc. (la protección de los intereses del niño concebido en el matrimonio, la estabilidad de las relaciones contractuales), entre muchas otras. En este aspecto, se ha puesto de relieve que las presunciones legales, como normas jurídicas, son instrumentos ideados para garantizar ciertos valores. Pero lo peculiar de las normas que establecen presunciones legales es que el mecanismo utilizado para garantizar tales valores es a través de la regulación de la carga de la prueba. ${ }^{40}$

Es importante destacar, por lo demás, que el legislador no es el único que recurre a este mecanismo para regular la carga de la prueba. En el ámbito jurisprudencial se produce un fenómeno similar al de las presunciones legales relativas que los juristas italianos han identificado con el nombre de "presunciones jurisprudenciales" (presunzioni giurisprudenziali). Su utilización es frecuente en el ámbito de la responsabilidad civil -médica, profesional, etc.-, pero también suele aplicarse en otros ámbitos. Ahora bien, el hecho de que tales presunciones no estén establecidas legalmente no implica que se trate de presunciones simples (o judiciales). Estas últimas son, como se verá, inferencias que parten de un hecho conocido para remontar a un hecho desconocido que se quiere acreditar. Las presunciones jurisprudenciales, en cambio, son reglas que dispensan de la carga de acreditar un hecho y trasladan a la contraparte la carga de la prueba de lo contrario. En estos casos, el juez no formula una inferencia entre hechos, ni extrae consecuencias cognoscitivas respecto de su existencia. Se trata de una operación equiparable a la que realiza el legislador cuando establece una presunción legal relativa y, al igual que esta, no es un mecanismo para determinar la existencia de los hechos. ${ }^{41}$

\footnotetext{
40 WRÓBLEWSKI (1974).

41 Vid. al respecto, Verde (1971); VAllebona (1988); TARUfFo (1991), p. 3. Para este último, debe excluirse que las presunciones jurisprudenciales constituyan una especie de híbrido entre las presunciones legales relativas y las presunciones simples, dada la completa diversidad de estas dos figuras. Tampoco se trata a su juicio de un tertium genus que se coloque al lado de estos dos tipos de presunciones dado que la estructura característica de las presunciones jurisprudenciales es análoga a la de las presunciones legales relativas: dispensan de la carga de acreditar un hecho e invierten la carga de la prueba de lo contrario a la contraparte. Podría tratarse de un mecanismo a mitad de camino entre las presunciones simples y las presunciones legales relativas, en el sentido de que son
} 
Gama - Concepciones y tipología de las presunciones...

Sin embargo, el establecimiento de presunciones jurisprudenciales que tengan el efecto de invertir la carga de la prueba no está exento de dificultades. Si bien hay algunos ordenamientos que otorgan facultades al juzgador para aplicar las reglas legales de distribución de la carga de la prueba de acuerdo con los principios de disponibilidad y facilidad probatoria, no está claro que los jueces tengan poderes para realizar, en un caso concreto, una distribución de las cargas probatorias distinta a la que está prevista legalmente. ${ }^{42}$ La cuestión resulta aún más compleja en los ordenamientos que no hacen ninguna referencia al respecto. ${ }^{43}$ Por otra parte, en el ámbito doctrinal no hay un acuerdo al respecto. Algunos sectores doctrinales son favorables a la inversión de la carga de la prueba para garantizar los principios de facilidad y disponibilidad probatoria. ${ }^{44}$ No obstante, algunos autores han puesto de relieve los problemas que entraña la inversión de la carga de la prueba por parte del juez. Se ha observado en este sentido que el recurso a este mecanismo puede producir situaciones de incertidumbre e inseguridad para las partes. Se señala, asimismo, que con su utilización se corre el riesgo de vulnerar el principio de contradicción al manipular las cargas probatorias de una manera discrecional. ${ }^{45}$ Siendo conscientes de estos peligros, algunos autores han señalado que la motivación que realice el juez para invertir la carga de la prueba, así como la estabilidad y continuidad de los precedentes proporcionan seguridad jurídica para las partes. Con todo, hay un problema de fondo que continúa estando presente. A saber, si resulta justificado que el juez invierta la carga de la prueba apartándose de la distribución que el legislador determinó previamente para una generalidad de casos. Se trata de una tarea que, en principio, parece estar reservada para el legislador. Por este motivo, es una operación que requiere el sometimiento por parte del juez a controles y parámetros claros y rigurosos que justifiquen una determinación de tal naturaleza.

\section{Presunciones simples}

La noción de "presunción simple" se define tradicionalmente como la inferencia en la que a partir de determinados hechos y a través de una o varias máximas de experiencia, el juez extrae conclusiones acerca de la existencia de un hecho desconocido que se considera relevante para efectos de la decisión. La presunción simple se concibe de este modo como un instrumento cognoscitivo de carácter inmediato e indirecto que es utilizado por el juez para la determinación de los

establecidas por el juez para modificar la distribución de la carga de la prueba, aun cuando no han sido establecidas en la ley.

42 Este es el caso del ordenamiento español. Vid. el artículo 217 numeral 6 de La ley de Enjuiciamiento Civil (1/2000). Sobre ello vid. FERNÁNDEZ LÓPEZ (2006).

43 Tal es el caso de Italia, donde las opiniones doctrinales respecto de la inversión de la carga de la prueba por parte del juez son bastante críticas. Vid. principalmente PATTI (1987) y TARUFFO (1995).

${ }^{44}$ FERNÁNDEZ LóPEZ (2006).

45 TARUFFO (1995), p. 77. 
hechos. ${ }^{46}$ El análisis de esta figura exige clarificar, de manera preliminar, los componentes que integran el razonamiento presuntivo; esto es, examinar las nociones de "hecho conocido", "hecho desconocido" y "máximas de experiencia". Este examen es pertinente a fin de problematizar la complejidad del razonamiento presuntivo. De manera preliminar, es conveniente comenzar dicho análisis mostrando algunas de las distintas expresiones que los juristas utilizan para referirse a este mismo mecanismo probatorio, así como realizar algunos comentarios sobre los requisitos -establecidos legal o jurisprudencialmente- que deben cumplir las presunciones simples para que sean atendibles.

Al tratar de analizar las presunciones simples es importante advertir algunas de las distintas expresiones utilizadas por los juristas en el discurso jurídico. Entre estas se encuentran expresiones como las siguientes: "presunciones judiciales", "presunciones humanas", "praesumptiones hominis", "prueba de presunciones", "prueba presuntiva", "razonamiento presuntivo", "prueba indiciaria", "prueba de indicios", "prueba circunstancial", "prueba de conjeturas", "prueba indirecta", "inferencias indiciarias". Estas expresiones son utilizadas generalmente como sinónimos, si bien algunas de ellas son más usuales en determinadas culturas jurídicas o se utiliza una u otra expresión en función del énfasis que se ponga en alguno de sus componentes o en las cualidades de inferencia presuntiva. La utilización de diversos nombres para designar el mismo concepto podría deberse, como advirtió Carnelutti, a la falta de contacto entre las distintas ramas de la ciencia del Derecho. ${ }^{48}$ No obstante, los juristas suelen convenir hoy día en que las expresiones antes indicadas hacen referencia a un mecanismo de carácter mediato o indirecto para la determinación de los hechos en el proceso, y que no habría diferencias de fondo entre la prueba indiciaria o circunstancial propia del derecho penal y la prueba de presunciones (o simplemente "presunciones") típica del derecho civil. ${ }^{49}$

En cuanto a la clarificación de los componentes del razonamiento presuntivo es importante poner de relieve lo siguiente. El primer componente estructural de las presunciones simples está conformado, como hemos dicho, por los hechos conocidos. Por "hecho conocido" se entiende, como ha advertido Michele Taruffo, "cualquier circunstancia de hecho que el juez conozca en los modos admitidos por las leyes procesales". En este contexto, revisten el carácter de "hecho conocido" los hechos probados en el juicio, los hechos reconocidos y admitidos como verdaderos por las partes, los hechos notorios y, en general,

\footnotetext{
46 En relación con la noción de "presunción simple" vid. especialmente TARUFFO (1974); del mismo autor (2002), esp. pp. 471 y ss. Vid. también CORDOPATRI (1986), pp. 286 y ss.

${ }^{47}$ LEguisAmón (1991).

48 Cit. por MuÑoz SABATÉ (1983), p. 242.

49 Entre los autores que sostienen que se trata esencialmente del mismo fenómeno, vid. TARUFFO (1991); Belloch Julbe (1992); Devis Echandía (1988), p. 607. En sentido contrario, vid. CARRERAS (1962), p. 411 quien diferencia la prueba de presunciones de la prueba indiciaria afirmando que en la primera se produce un juicio de probabilidad, mientras que se daría un juicio de certeza en la segunda.
} 
Gama - Concepciones y tipología de las presunciones...

"todas las circunstancias de las que tenga el conocimiento el juez como resultado del proceso (como el comportamiento de las partes, por ejemplo)". ${ }^{0}$ Cobra relevancia en este contexto la noción de "indicio", entendida como "hecho conocido" o "fuente de presunción", ${ }^{11}$ en la medida que hace referencia a la premisa de la inferencia presuntiva. A juicio de Taruffo, puede tener el carácter de indicio "cualquier cosa, circunstancia o comportamiento que el juez considere significativo en la medida en que de él puedan derivarse conclusiones relativas al hecho a probar" ${ }^{2}$

El segundo componente está conformado por los hechos desconocidos. Por "hecho desconocido" se entiende todo hecho respecto del cual no existen pruebas idóneas para demostrar su existencia o inexistencia, y que se considera que debe ser acreditado para los fines de la decisión. El "hecho desconocido", por tanto, es un hecho no probado pero relevante en el juicio. ${ }^{53}$

El tercer y último componente del razonamiento presuntivo es el enlace entre el hecho conocido y el hecho desconocido. Al respecto, si se tiene en cuenta que la presunción simple consiste en una inferencia en la que a partir de un hecho conocido se extraen consecuencias sobre la existencia (o inexistencia) de un hecho desconocido, el enlace de la presunción simple consiste en un enunciado de carácter general que es utilizado para pasar de un hecho a otro. Este enunciado se forma, por lo general, a partir de criterios de carácter cognoscitivo que establecen una conexión entre la clase de hechos a la que pertenece el hecho conocido y la clase de hechos a la que pertenece el hecho desconocido, de tal manera que cuando el hecho conocido es individualizado en un caso concreto, es posible formular conclusiones respecto a la existencia del hecho desconocido. Estos criterios suelen ser agrupados en la dogmática jurídica continental bajo la noción de "máximas de experiencia". ${ }^{4}$

\footnotetext{
50 TARUFFO (1991). Esto supone que de este extenso conjunto quedan excluidos los hechos que forman parte del conocimiento privado del juez (sobre ello vid. STEIN (1999)). A partir de lo anterior se deriva una importante consecuencia advertida por Michele Taruffo, a saber, "que el concepto de presunción simple es demasiado amplio, y comprende todos los casos en los que la verdad de un hecho no viene determinada sobre la base de una prueba que tenga directamente como objeto tal hecho, sino que partiendo de un hecho conocido (o porque ha sido acreditado, o porque ha sido percibido por el juez en juicio) para extraer conclusiones respecto de otro hecho que es necesario conocer para los fines de la decisión".

51 A pesar de la ambigüedad de esta expresión, la doctrina continental considera que este es el sentido central y riguroso del término "indicio". Sobre ello vid. MUÑOZ SABATÉ (1983) y TARUFFO (2002), esp. pp. 479 y ss.

52 TARUFFO (2002).

53 TARUFFO (1991).

54 El mérito de haber individualizado la noción de "máxima de experiencia" se atribuye a Stein: "Son definiciones o juicios hipotéticos de contenido general, independientes del caso concreto a decidir en el proceso y de sus circunstancias singulares, adquiridas mediante la experiencia, pero autónomas respecto de los casos singulares de cuya observación se infieren, y fuera de los cuales presentan valor para otros casos". Cfr. STEIN (1999).
} 
Dos observaciones resultan fundamentales al tratar el tercer y último elemento de las presunciones simples. En primer lugar, es importante subrayar, como ha puesto de relieve Michele Taruffo, que de las características del criterio utilizado para formular la presunción dependerá la naturaleza del razonamiento presuntivo. En segundo lugar, el criterio utilizado como enlace de la presunción determina el valor cognoscitivo de las conclusiones extraídas. Estas dos observaciones son relevantes porque en el discurso de los juristas está muy difundida la idea de que la noción de "máxima de experiencia" integra un conjunto determinado y uniforme de criterios de características similares. En contra de esta orientación, autores como Taruffo han puesto de relieve que se trata de una noción sumamente amplia e indefinida que integra un conjunto amplio, indefinido y heterogéneo de criterios. El extenso conjunto de enunciados que los juristas suelen reconducir (a menudo de manera inadvertida) a la noción de máxima de experiencia abarca desde leyes naturales o leyes lógicas a nociones científicas, generalizaciones empíricas, tendencias genéricas, reglas extraídas del sentido común, frecuencias estadísticas, opiniones o perjuicios difundidos, nociones vulgarizadas y superficiales provenientes de distintos campos (psicología, economía, sociología, ética, etc.).

De lo anterior se deriva una consecuencia que es importante advertir: de la heterogeneidad de criterios que integran la noción de máximas de experiencia se desprende una correspondiente heterogeneidad de tipos de razonamiento presuntivo. En este sentido, como pone de relieve Taruffo, cuando la máxima de experiencia consiste en un enunciado de carácter universal (como una ley natural o científica) la presunción deriva de una inferencia deductiva capaz de dotar de certeza a la conclusión extraída a partir de un hecho conocido. Si bien este tipo de inferencias son posibles de formular en el terreno jurídico, son poco frecuentes. En la mayor parte de los casos, sin embargo, la máxima de experiencia expresa únicamente una conexión probable entre el hecho conocido y el hecho desconocido, con grados de probabilidad sumamente diversos. En estos casos, la presunción deriva de una inferencia inductiva que solo es capaz de conducir a conclusiones probables. En otros términos, el grado de aceptabilidad de la inferencia presuntiva está determinado, por tanto, por la naturaleza y el contenido de la máxima de experiencia utilizada como regla de inferencia.

Las consideraciones anteriores permiten abordar con mayor claridad el problema de los requisitos normativamente establecidos para la admisión de las presunciones simples. En el discurso del legislador y del juez es posible distinguir dos modelos. De acuerdo con el primer modelo, las presunciones simples solo serán admitidas si son "graves, precisas y concordantes" para que puedan ser aceptadas como prueba de un hecho. ${ }^{56}$ En un segundo modelo se exige que exista

\footnotetext{
55 TARUFFO (1992).

${ }^{56}$ Es el que se establece, por ejemplo, en el Civil Francés (art. 1353) y en el italiano (art. 2729). Resulta impropio hablar de "admisibilidad" en este contexto, a pesar de que la ley utilice este término. En este sentido, por ejemplo, el artículo 2727 del C.C. italiano establece que las
} 
Gama - Concepciones y tipología de las presunciones...

un enlace "preciso y directo" entre el hecho conocido y el hecho desconocido, que sea acorde con las reglas del criterio humano. Para los propósitos del presente análisis es conveniente realizar un examen general de estos criterios.

Tradicionalmente la doctrina ha venido considerando que una inferencia presuntiva es precisa o directa cuando es unívoca o inequívoca, es decir, cuando permite extraer conclusiones referidas a la existencia del hecho a probar y no a otros hechos. ${ }^{57}$ Sin embargo, el criterio de univocidad no ha de ser entendido de forma absoluta, de modo tal que el hecho conocido fundamente una única inferencia y ésta se refiera al hecho a probar. Esto solo ocurre cuando el criterio de inferencia utilizado es un enunciado universal. En cambio, cuando se utiliza un criterio de carácter probable, y por consiguiente no necesario, es del todo posible que de un mismo hecho (o conjunto de hechos) puedan derivarse conclusiones diversas. Lo importante en este contexto no es que de un hecho puedan inferirse, como de hecho ocurre, conclusiones referidas a otros hechos, sino que la inferencia presuntiva en cuestión tenga un mayor grado de probabilidad que las inferencias restantes. ${ }^{58} \mathrm{~A}$ esta misma idea apunta fundamentalmente el requisito de gravedad de las presunciones. La doctrina considera que la gravedad no atiende propiamente al grado de convicción que la presunción genera en el juez, sino al grado de aceptabilidad que la presunción atribuye al conocimiento del hecho conocido sobre la base del hecho conocido. Nuevamente, que la presunción sea grave no implica que la conclusión que se extrae acerca de la existencia del hecho desconocido tenga que determinarse con absoluta certeza. Esto solamente ocurre, como se ha dicho, cuando la inferencia presuntiva se basa en una ley natural o científica. Por el contrario, cuando el criterio inferencial consiste en una máxima de la experiencia derivada del sentido común, la existencia del hecho desconocido

presunciones solo serán admitidas si son "graves, precisas y concordantes". Al respecto, Taruffo explica que se trata de una norma de prueba legal negativa "en la medida en que excluye que las presunciones - entendidas como resultado de las inferencias formuladas por el juez- puedan constituir prueba del hecho si no presentan aquellos requisitos". Cfr. TARUFFO (2002), p. 472.

${ }^{57}$ LESSONA (1964).

58 Taruffo explica claramente esta idea cuando señala que: "lo que interesa es que, sobre un fondo de irreducible equivocidad teórica, se llegue sin embargo a formular una inferencia dotada de univocidad práctica: esta se produce cuando la inferencia en cuestión atribuye un grado prevaleciente de confirmación a la hipótesis sobre el hecho a probar, es decir, cuando entre las diversas conclusiones que se pueden obtener a partir del 'hecho conocido' la más probable es aquella que confirma la hipótesis sobre el hecho a probar. Así, pues, se dispone de una inferencia presuntiva 'precisa' cuando esta produce conclusiones probables sobre el hecho a probar, es decir, cuando la conclusión más probable que de ella se puede extraer se refiere a ese hecho". Cfr. TARUFFO (2002), p. 472. Como puede advertirse, la referencia al grado de probabilidad exigido para la aceptación de la presunción simple se vincula con el umbral fijado por el estándar de prueba. En este punto, la referencia al criterio de "mayor grado de probabilidad" estaría vinculado con el estándar de prueba que tradicionalmente se aplica al proceso civil. Un estudio más detallado requeriría un análisis detenido sobre el estándar de prueba exigido para la prueba por presunciones en función del tipo de proceso. Sobre este punto, véase un tratamiento general del estándar de prueba y sus problemas en LAUDAN (2013). 
deriva de una inferencia probable. Desde esta perspectiva, que la presunción sea grave quiere decir que la conclusión extraída de la inferencia presuntiva sea la más probable en comparación con las hipótesis restantes. Finalmente, el requisito de concordancia establece que cuando las inferencias presuntivas se encuentran sustentadas en una variedad de indicios o hechos conocidos estos deben converger hacia la misma conclusión. Aquí es importante puntualizar que no se trata de una concordancia absoluta entre una pluralidad de indicios (o hechos conocidos) y el hecho que se intenta probar. Sería suficiente, como hace notar Michele Taruffo, que solo algunos "convergieran hacia una misma conclusión, con la condición de que las otras inferencias posibles no atribuyan un grado de confirmación igual o superior a una conclusión distinta sobre el hecho a probar". El requisito de concordancia, por tanto, no debe ser entendido de forma absoluta, sino relativa, atendiendo a la mayor prevalencia de la hipótesis presuntiva. ${ }^{59}$

${ }^{59}$ Ibid. 
Gama - Concepciones y tipología de las presunciones...

\section{BIBLIOGRAFÍA}

* Aguiló, J. (1999): "Nota sobre 'Presunciones' de Daniel Mendonca" en Doxa, (22).

* ÁlvareZ SÁNCHEZ DE MOVELLÁN, P. (2007): La prueba por presunciones: particular referencia a su aplicación judicial en supuestos de responsabilidad extracontractual (Granada, Comares).

* ANDrioli, V. (1966): "Presunzioni (Diritto civile e Diritto processuale civile)" en Novissimo Digesto Italiano (XIII) pp. 766-772 (Torino, Unione Tipografico-editrice torinese).

* BELlOCH JULBE, J. A. (1992): "La prueba indiciaria" en La sentencia penal, Cuadernos de Derecho Judicial, pp. 29-93 (Madrid, CGPJ).

* CARnelutTi, F. (1982): La prueba civil (Buenos Aires, Depalma).

* CARreras, J. (1962): "Naturaleza jurídica y tratamiento de las presunciones", Estudios de Derecho Procesal, M. F. y. J. Carreras, pp. 337-413 (Barcelona, Bosch).

* Climent DURÁN, C. (2005): La prueba penal, $2^{a}$ ed. (Valencia, Tirant lo Blanch).

* COMOglio, L. P., FERRI, C. (et al.) (2005): Lezioni sul processo civile, $3^{\mathrm{a}}$ ed. (Bologna, Il Mulino).

* CORDopatri, F. (1986): "Presunzione (Teoria generale e diritto processuale civile)", Enciclopedia del Diritto (XXXV) pp. 274-304 (Torino, A. Falzea, Giuffrè Editore).

* Couture, E. J. (1993): Fundamentos del derecho procesal civil, $3^{\mathrm{a}}$ ed. (Buenos Aires, Depalma).

* DEVIS ECHANDÍA, H. (1988): Teoría general de la prueba judicial, 6a ed. (Buenos Aires, Zavalia).

* ESEVERri martíneZ, E. (1995): Presunciones legales y derecho tributario (Madrid, Marcial Pons).

* FABBRINI, G. (1991): "Note in tema di presunzioni legali" en Rivista Trimestrale di Diritto e Procedura Civile (XLV-3). (1996) "Presunzioni" en Digesto delle Discipline Privatistiche, Serione Civile, XIV (PosProced) pp. 279-293 (Torino).

* FERNÁNDEZ LÓPEZ, M. (2006): La carga de la prueba en la práctica judicial civil (Madrid, La Ley).

* GARBERÍ llobregAT, J. y BUITRÓN RAMÍREZ, G. (2004): La prueba civil: doctrina, jurisprudencia y formularios sobre prueba y medios de prueba en la nueva Ley de Enjuiciamiento Civil (Valencia, Tirant Lo Blanch).

* ITAliA, V. (1999): Le presunzioni legali (Milano, Giuffré).

* LAUDAN, L. (2013): Verdad, error y proceso penal (Barcelona, Marcial Pons).

* Leguisamón, H. E. (1991): Las presunciones judiciales y los indicios (Buenos Aires, Depalma).

* LESSONA, C. (1964): Teoría general de la prueba en derecho civil (Madrid, Instituto Editorial Reus).

* LÉVY, J.-P. (1965): “L' evolution de la preuve dès origines à nos jours. Sinthèse générale" en Recueils de la Societè J. Bodin, (XVII) pp. 9-70 (Bruxelles).

* LIEBMAN, E. T. (2007): Manuale di diritto processuale civile: principi, $7^{\mathrm{a}} \mathrm{ed}$. (Milano, Dott. A. Giuffrè).

* MANDrioli, C. (2006): Diritto processuale civile, $18^{a}$ ed. (Torino, G. Giappichelli).

* MiCHELI, G. A. (1961): La carga de la prueba (Buenos Aires, Ediciones Jurídicas EuropaAmérica).

* MiRANDA ESTRAMPES, M. (1997): La minima actividad probatoria en el proceso penal (Barcelona, Bosch).

* MONTERO AROCA, J. (2002): La prueba en el proceso civil, $3^{\mathrm{a}}$ ed. (Madrid, Civitas). 
* MUÑOZ SABATÉ, L. (1983): Técnica probatoria: estudios sobre las dificultades de prueba en el proceso (Barcelona, Praxis).

* Oliva SANTOS, A. D. L. y DÍEZ-PICAZO JIMÉNEZ, I. (2004): Derecho procesal civil: el proceso de declaración, $3^{a}$ ed. (Madrid, Centro de Estudios Ramón Areces).

* PAllares, E. (1963): Diccionario de Derecho Procesal Civil, 5ª ed. (México, Porrúa).

(1983) Derecho procesal civil, $10^{a}$ ed. (México, Porrúa).

* PATTI, S. (1987): Prove, disposizioni generali : art. 2697-2698 [del Codice civile] : Libro sesto, Della tutela dei diritti (Bologna, Zanichelli).

* PRIETO CASTRO Y FERRÁNDIZ, L. (1982): Tratado de derecho procesal civil: proceso declarativo, proceso de ejecución (Pamplona, Aranzadi).

* RAMPONI, L. (1890): La teoria generale delle presunzioni nel diritto civile italiano (Torino, F. Bocca).

* Rosenberg, L. (2002): La carga de la prueba, $2^{a}$ ed. (Montevideo, B de F.).

* SACCO, R. (1957): "Presunzione, natura costitutiva o impeditiva del fatto, onere della prova" en Rivista di Dirito Civile (2) pp. 399-423.

* SÁnCHEZ PINO, A. J. (1995): Presunciones y ficciones en el impuesto sobre la renta de las personas físicas (Huelva, Universidad de Huelva).

* Serra Domínguez, M. (1963): Normas de presunción en el Código Civil y ley de arrendamientos urbanos (Barcelona, Nauta).

(1991) “Comentarios a los arts. 1249 a 1253 del Código Civil”, Comentarios al Código civil, M. Albadalejo, (XVI-2) pp. 543-718 (Madrid, Edersa).

* STEIN, F. (1999): "El conocimiento privado del juez" (Madrid, Centro de Estudios Ramón Areces: XIV).

* TARUfFO, M. (1974): “Certezza e probabilità nelle presunzioni” en Foro Italiano (V). (1991) "Presunzioni (Diritto Processuale Civile)" Enciclopedia Giuridica Teccom (XXIV) (Roma, Instituto della Enciclopedia Italiana). (1992) "Libero Convincimento del Giudice", Enciclopedia Giuridica, Teccom (Roma, Instituto della Enciclopedia Italiana). XIII). (1995) "Onere della prova", Digesto delle Discipline Privatistiche. Sequione Civile (vol.

(2002) La prueba de los hechos (Madrid, Trotta).

* VAlLebonA, A. (1988): L'onere della prova nel diritto del lavoro (Padova, Cedam).

* VERDE, G. (1971): “Le presunzioni giurisprudenziali”, Foro Italiano (V) pp. 177-192. (1974) L'onere della prova nel processo civile (Napoli, Jovene Editore).

* WRÓBLEWSKI, J. (1974): "Structure et fonction des présomptions juridiques" en Les présomptions et les fictions en Droit (Bruxelles, Bruylant). 